\title{
veras
}

ISSN 2236-5729

\section{Caminhos percorridos para o desenvolvimento de uma prática artístico-educativa na escola: uma inspiração freireana'}

\section{The paths taken to develop an artistic and educational practice at school: a freirean inspiration}

\author{
Alexandre Saul é Mestre e Doutorando em Educação pela \\ Pontifícia Universidade Católica de São Paulo (PUC-SP). Tem \\ participado de atividades de formação de educadores em \\ diversos municípios, dialogando sobre currículo, avaliação e \\ práticas educativas na perspectiva crítico-libertadora. É também \\ ator do Grupo de Teatro Arte Tangível (www.artetangivel. \\ wordpress.com).
}

Contato: asaul@hotmail.com

\section{Resumo}

Este texto relata os caminhos percorridos para o desenvolvimento de uma prática artístico-educativa, em um Centro de Educação de Jovens e Adultos, com a intenção de estimular a reflexão crítica dessa comunidade escolar sobre algumas de suas situações-limites e a mobilização para superá-las. Por meio da observação participante, de abordagem qualitativa, foi sendo construído um quefazer teatral inspirado na proposta político-pedagógica de Paulo Freire para codificar, em linguagem teatral, e debater com a comunidade escolar, as situações-limites por ela vivenciadas. Objetivou-se desenvolver um teatro no qual o diálogo, como entendido e proposto por Freire, assumiu um papel central no que se refere à construção de conhecimento e a uma prática emancipatória. Os resultados demonstraram a viabilidade e a relevância de uma experiência como essa na Educação de Jovens e Adultos, destacando-se seu potencial de ampliar as possibilidades de leitura da realidade dos participantes e gerar ações de cidadania ativa. Em acréscimo, os resultados apontaram implicações educacionais para o currículo escolar, acenando com possibilidades de enraizamento da prática teatral realizada.

1. Uma versão deste trabalho foi apresentada no "X Encontro de Pesquisadores do Programa Educação: Currículo da PUC-SP", em 2011 


\begin{abstract}
This paper reports the paths taken to develop an artistic and educational practice in an Education Center for Youth and Adults, with the intention of stimulating critical reflection of the school community about some of their limit-situations and mobilize to overcome them. Through participant observation, on a qualitative approach, there was built a theater practice inspired by the politicalpedagogical proposal of Paulo Freire, to encode, in theatrical language, and to discuss with the school community, the limit-situations experienced by them. The objective was to develop a theater in which the dialogue, as proposed by Freire, assumed a central role with regard to the construction of knowledge and an emancipatory practice. The results demonstrated the feasibility and relevance of such an experience with Youth and Adults, highlighting its potential to expand the ability of "reading reality" of the participants and generate actions of active citizenship. In addition, the results suggest implications for the educational curriculum, waving rooting possibilities of theater practice performed. Keywords: theater; dialogue; Paulo Freire.
\end{abstract}

\title{
Introdução
}

É preciso ousar, no sentido pleno desta palavra, para falar em amor
sem temer ser chamado de piegas, de meloso, de acientífico, senão de
anticientífico. É preciso ousar para dizer cientificamente que estudamos,
aprendemos, ensinamos, conhecemos com nosso corpo inteiro. Com
sentimentos, com as emoções, com os desejos, com os medos, com as
dúvidas, com a paixão e também com a razão crítica. Jamais com esta
apenas. É preciso ousar para jamais dicotomizar o cognitivo do emocional.
Paulo Freire

Sou formado em Ciência da Computação pela Pontifícia Universidade Católica de São Paulo (PUC-SP). Na época de minha graduação fui um assíduo espectador de teatro. Esse interesse me instigou a experienciar o outro lado da relação palco-plateia e assim ingressei no grupo de teatro Arte Tangível. Por meio das atividades desenvolvidas como ator de teatro, no Arte Tangível, em diversos espaços da cidade de São Paulo, mas, principalmente, em escolas públicas, percebi a potencialidade que um teatro crítico tem de proporcionar reação aos esquemas rígidos e pouco criativos da educação. 
0 acúmulo de experiência com o trabalho no teatro me desafiou a pensar em uma prática educativa com a intenção de contribuir para a transformação da realidade das comunidades escolares, por meio do estímulo à reflexão crítica sobre temas significativos para elas, mediada pela prática teatral. Por isso decidi ingressar no Mestrado e me dedicar exclusivamente à área da Educação, em sua interseção com o teatro. Essa decisão implicou uma ruptura e não poderia ser diferente. Paulo Freire ensina que:

\begin{abstract}
Não posso ser professor se não percebo cada vez melhor que, por não ser neutra, minha prática exige de mim uma definição. Uma tomada de posição. Decisão. Ruptura. Exige de mim que escolha entre isto e aquilo. Não posso ser professor a favor de quem quer que seja e a favor de não importa o quê. Não posso ser professor a favor simplesmente do Homem ou da Humanidade, frase de uma vaguidade demasiado contrastante com a concretude da prática educativa (Freire, 2008, p. 102).
\end{abstract}

Passei a viver outros sonhos! Encontrei inspiração nessa frase de Shakespeare para a nova direção de minha trajetória acadêmicoprofissional: "Se teus sonhos estão nas nuvens, não te preocupes, eles estão no lugar certo; agora construa os alicerces."

A pesquisa relatada neste texto, desenvolvida em nível de Mestrado na PUC-SP, trabalhou com as ideias centrais do pensamento freireano no que se refere à construção de conhecimento e a uma prática emancipatória, articuladas a um fazer teatral, com intenção de codificar e debater com uma comunidade escolar da cidade de São Paulo as situaçõeslimites por ela vivenciadas em seu próprio ambiente. Refiro-me a situações-limites como entendidas por Paulo Freire, ou seja, situações de opressão e autoritarismo que se constituem em impedimentos para o processo de humanização e libertação dos seres humanos. Freire destaca, porém, que as situações-limites

\footnotetext{
[...] não devem ser tomadas como se fossem barreiras insuperáveis, mais além das quais nada existisse. No momento mesmo em que os homens as apreendem como freios em que elas se configuram com obstáculos à sua libertação, se transformam em "percebidos destacados" em sua "visão de fundo". Revelam-se, assim, como realmente são: dimensões concretas e históricas de uma dada realidade. Dimensões desafiadoras dos homens, que incidem sobre elas através de ações que Vieira Pinto chama de "atoslimites" - aqueles que se dirigem à superação e à negação do dado, em lugar de implicarem na sua aceitação dócil e passiva. [...] Para Vieira Pinto, as "situações-limites não são o contorno infranqueável onde terminam as
} 
possibilidades, mas a margem real onde começam todas as possibilidades"; não são "a fronteira entre o ser e o nada, mas a fronteira entre o ser e o ser mais" (Freire, 1987, p. 90).

Foi desenvolvida uma prática educativa com implicações curriculares em suas dimensões cognitiva, política, socioafetiva e estética, com a perspectiva de investigar possíveis caminhos para estimular pensamentos e práticas comprometidos com a transformação dos contextos sociais dessa comunidade escolar.

Esta pesquisa caracteriza-se como uma investigação participante. Chizzotti (2008) apresenta referências para fundamentar a metodologia de investigações que se inserem no quadro das pesquisas qualitativas. De acordo com esse autor:

\footnotetext{
[...] Se, de outro lado, o pesquisador supõe que o mundo deriva da compreensão que as pessoas constroem no contato com a realidade nas diferentes interações humanas e sociais, será necessário encontrar fundamentos para uma análise e para a interpretação do fato que revele o significado atribuído a esses fatos pelas pessoas que partilham dele. Tais pesquisas serão designadas qualitativas, termo genérico para designar pesquisas que, usando ou não, quantificações, pretendem interpretar o sentido do evento a partir do significado que as pessoas atribuem ao que falam e fazem (pp. 27-28).
}

Esse tipo de investigação é uma ação conscientemente política. Paulo Freire considera importante insistir no caráter político da atividade científica: "A quem sirvo com minha ciência? (...) devemos ser coerentes com a nossa opção, exprimindo a nossa coerência na nossa prática." (Freire, 1981, p. 36). 0 conhecimento construído em conjunto com os sujeitos pesquisados está intencionalmente comprometido com propostas para a mudança de pensamentos e práticas tendo, no horizonte, a transformação da realidade pesquisada.

Pesquisar, na perspectiva freireana, exige assumir uma atitude de procura permanente pela compreensão cada vez mais crítica e acurada das intervenções dos seres humanos no mundo e com o mundo, da razão de ser dos fatos como vem sendo, possibilitando gerar novas ações para a construção de um mundo mais solidário e mais justo. Ao escrever sobre sua concepção de pesquisa, Freire assim se manifesta: "Pesquiso para constatar, constatando, intervenho, intervindo educo e me educo. Pesquiso para conhecer o que ainda não conheço e comunicar ou anunciar a novidade" (Freire, 2008, p. 39). 
Esse constante movimento de procura e reprocura, impulsionado pela curiosidade dos seres humanos exige, de um lado, que se busque conhecer o que já se sabe acerca de um objeto de conhecimento e de outro, uma abertura à construção do novo conhecimento que superará o velho. Observe-se, porém, que não é possível saber tudo o que foi produzido acerca de certo objeto de conhecimento, mas parte do que foi produzido. Isso implica dizer que o conhecimento será sempre uma seleção e será tanto mais significativo quanto mais estiver contextualizado e responder a que serve e a quem serve. A construção do novo conhecimento, na pesquisa, não se identifica, necessariamente, com o inédito; embora um conhecimento possa já ter sido anteriormente gerado, poderá ser reconhecido como novo para aqueles que o produzem sob novas circunstâncias ou características, no espaço/tempo dessa produção.

\section{O contexto da pesquisa: um centro de educação de jovens e adultos}

É importante compreender a Educação de Jovens e Adultos (EJA) como uma ação cultural e política que permite lutar por direitos que têm sido negados nas trajetórias humanas e escolares de muitos jovens e adultos brasileiros. Encontrei em Arelaro e Kruppa (2007) um destaque especial a respeito das características que os educandos da EJA trazem para a situação de ensino-aprendizagem. Estas estão para além dos motivos utilitaristas e instrumentais de "aprender para" e se relacionam ao gosto pela convivência humana. Segundo as autoras:

\footnotetext{
A EJA está no contexto das políticas sociais de melhoria da qualidade de vida, que visam à inserção de milhares de pessoas numa sociedade de direitos. De um lado a compreensão e a busca de formas de superação para as discriminações de classe, de gênero, de raça e também de idade, frutos de um modelo econômico social e político, individualista e segregador devem ser colocadas no universo de seus objetivos. De outro lado, está a exigência da EJA em compreender e alargar as formas de organização presentes nas rotinas de sobrevivência dessa população, elementos de resistência a essas discriminações e que se constituem num resíduo do humano, cotidianamente negado pelo sistema capitalista, que classifica e ordena a vida social para fins de controle (Arelaro; Kruppa, 2007, p. 121122).
}

Na esteira dessa opção política por uma educação que propugna relações dialógicas e solidárias na luta por direitos, esta pesquisa procurou desenvolver práticas artístico-educativas, na escola, 
que pudessem colaborar para a superação de desarmonias e necessidades que se constituem em empecilhos para a realização de uma educação pública, popular, democrática e de qualidade. Os caminhos de investigação se fundamentaram na matriz de pensamento de Paulo Freire que destaca a radicalidade do compromisso com a transformação social, o educando como sujeito de conhecimento, a urgência do diálogo, a convivência solidária, a importância da ética e da estética e o rigor no trabalho com os conceitos, jamais separado do desvelamento da realidade. Vale aqui recuperar as palavras de Freire: "Para mim a educação é simultaneamente um ato de conhecimento, um ato político e um ato de arte." (Freire apud Mclaren, 1987, p. 3).

Esta pesquisa foi realizada no Centro Integrado de Educação de Jovens e Adultos (CIEJA) Mandaqui que, a partir de 2010, passou a se chamar CIEJA Santana/Tucuruvi. Os CIEJAs foram criados em 2003 pela Prefeitura de São Paulo em substituição aos Centros Municipais de Educação Supletiva (CEMEs), buscando mudanças em sua estrutura e reformulações curriculares. Os objetivos centrais da nova estrutura são: a democratização do acesso e a permanência dos educandos, a democratização da gestão e a qualidade social da educação. O CIEJA é um programa de educação especialmente dirigido a jovens e adultos que não puderam cursar e concluir o Ensino Fundamental na idade própria, com ênfase na preparação para o mundo da cultura e na orientação para o trabalho. Embora a grande maioria das aulas seja de caráter convencional, o CIEJA Santana/Tucuruvi se preocupa em programar "aulas diferentes". Para isso, trabalha com diversos materiais didáticos e linguagens variadas - música, vídeo, teatro e realiza atividades educativas fora da escola, organizando visitas a teatros, exposições, mostras e outros espaços da cidade de São Paulo, seguidas de debate em sala de aula. A experiência procura envolver, também, toda a comunidade escolar.

\section{A aproximação com a escola: um pouco de história}

Em 2008, o grupo de teatro Arte Tangível realizava um projeto de circulação de espetáculos teatrais que incluía a apresentação gratuita, em escolas públicas da Zona Norte do município, do espetáculo "Sobre Sonhos e Esperança" - inspirado na vida e na obra do educador Paulo Freire, seguido de debate com o público.

Nessa ocasião, o grupo conheceu o CIEJA Santana/Tucuruvi e se interessou pela receptividade, pela proposta inclusiva e 
democrática da escola, que se mostrava aberta a contribuições externas visando à melhoria da qualidade do trabalho pedagógico que lá era realizado. 0 CIEJA entusiasmou-se pela linguagem artística e pelas temáticas trabalhadas pelo grupo de teatro que se propõe a discutir, de forma crítica, questões sociais, educativas e culturais. Esse encontro inaugurou um diálogo do qual nasceu o desejo mútuo de ampliar a parceria entre a escola e o grupo. Com a perspectiva de intervir na realidade sociocultural do bairro, esta pesquisa apresentou-se como uma possibilidade de estimular reflexões e ações, sobre e a partir de práticas da comunidade, para além de contatos pontuais, tomando como ponto de partida 0 diálogo entre o grupo de teatro e a comunidade escolar.

\section{A entrada na escola}

As ações efetivas para que fosse possível iniciar o desenvolvimento desta pesquisa no CIEJA foram iniciadas por meio de contatos telefônicos e reuniões no espaço escolar com o coordenador pedagógico, a diretora e a vice-diretora. Nas primeiras duas reuniões foi apresentada e debatida a proposta inicial da pesquisa, discutidas as primeiras ideias de logística, incluindo a definição dos sujeitos que participariam do trabalho e foi solicitada a autorização formal para realização desta pesquisaação. Nesses encontros foram preenchidos os documentos necessários para avaliação dos procedimentos de pesquisa pelo Comitê de Ética da PUC-SP.

Esse modo de entrar na escola e escutar os sonhos e as angústias dos gestores, incluindo-os na construção da proposta da pesquisa, foi fundamental para a garantia do prosseguimento da mesma e ampliação de suas chances de sucesso, por meio da busca de adesão de aliados. Em Conhecimento Oficial (1997), Michael Apple, ao relatar uma experiência interrompida de produção de filmes em uma instituição de correção juvenil questiona, ao lado de outras preocupações, se teria sido ingênuo e se deveria ter envolvido os administradores e o grupo de educadores mais diretamente em sua ação, desde o início do trabalho. Com isso, ele demonstra a importância do envolvimento dos gestores para um trabalho que se proponha a ser diferente do instituído, desde o primeiro momento, buscando a participação dos mesmos e a criação de vínculos com o trabalho. Isso vai além de pedir uma pura autorização. 


\section{Planejamento e execução das ações do grupo teatral}

Com inspiração no caminho para o desenvolvimento de um trabalho educativo com a comunidade escolar, apresentado por Paulo Freire no capítulo três da Pedagogia do Oprimido, foram propostos os seguintes momentos para o planejamento e execução das ações do grupo teatral, nesta pesquisa:

- Encontros com a comunidade escolar para debater situações dessa comunidade, a partir de reflexões de temas de uma peça teatral que se sintonizavam com questões críticas da comunidade, identificadas em uma leitura prévia de sua realidade concreta.

- Análise, pelo grupo de teatro, dos registros dos debates com a comunidade, para identificação de situações-limites e temas geradores para novos debates e seleção de falas significativas dos participantes, com a intenção de que estas integrassem o roteiro de encenação de uma recriação da peça teatral original.

- Preparação do roteiro de um espetáculo teatral com codificações de situações-limites registradas nos encontros.

- Criação e ensaio do espetáculo teatral com o grupo de atores.

- Preparação de encontros mensais com a comunidade escolar para prosseguir o diálogo sobre a temática levantada e discutir o desenvolvimento do trabalho artístico-teatral.

- Encenação da peça que combinava a história original e as codificações das situações-limites expressas, nos encontros, pelos educandos.

- Realização de debates após a apresentação da peça, para refletir criticamente sobre caminhos e ações possíveis para a transformação de aspectos da vida cotidiana da comunidade, a partir das situações codificadas no espetáculo.

Os momentos do fazer artístico-educativo aqui referidos guardam relação com as fases do caminho metodológico da educação problematizadora proposta por Freire desde os seus primeiros escritos para um trabalho de conscientização e consequente alfabetização. Essas fases incluem a investigação de palavras e temas geradores, a busca dos núcleos fundamentais dos temas em um processo de "redução" temática e a sua codificação/ descodificação. As características de cada uma dessas fases se 
interpenetram e podem ser encontradas em diferentes momentos do trabalho artístico-educativo desenvolvido nesta pesquisa.

Embora não seja adequado estabelecer uma relação unívoca entre as fases da proposta freireana e os momentos da construção do fazer teatral, a relação estabelecida entre as fases e os momentos é uma questão de ênfase. Isto porque em um mesmo momento, por exemplo, as características de diferentes fases da proposta de Freire estiveram presentes. Assim, a investigação temática teve ênfase no planejamento das ações do grupo teatral em conjunto com a coordenação e a direção da escola, na participação em atividades da escola e nos encontros com a comunidade escolar, em especial, nos primeiros. A busca pelos núcleos fundamentais dos temas geradores permeou todo o planejamento das atividades do grupo teatral. A codificação/descodificação figurou no planejamento das atividades do grupo teatral, nos ensaios e produção das obras teatrais, nos encontros teatrais pedagógicos, nas apresentações públicas de espetáculos, nos debates com espectadores e na avaliação e reflexão sobre as práticas.

A seguir, serão relatados os procedimentos utilizados em cada um dos diferentes momentos (sete), anteriormente elencados.

\section{Primeiros encontros com os educandos}

Em 2009 foram realizados os primeiros quatro encontros, em noites consecutivas, com cerca de vinte educandos, convidados pelos gestores do CIEJA que lhes fizeram breve apresentação da proposta da pesquisa. 0 grupo de educandos foi composto de jovens e adultos trabalhadores, em sua maioria moradores da região em que se localiza o CIEJA, pertencentes às classes populares, e que buscavam iniciar ou completar seus estudos do ensino fundamental no período noturno na Educação de Jovens Adultos (EJA). Esses encontros poderiam ser frequentados, também, por membros da comunidade escolar que não estivessem matriculados no CIEJA naquele momento (ex-alunos, amigos e familiares dos participantes). Os encontros tiveram seu formato inspirado nos Círculos de Investigação Temática, como propostos por Paulo Freire, nos quais os educandos dialogavam sobre a sua realidade concreta, sobre seus temas de interesse e a partir de suas experiências, com o objetivo de investigar a temática significativa da comunidade.

Após uma rodada de apresentações, todos os presentes foram amplamente esclarecidos sobre os objetivos do trabalho e 
foram colhidos aceites e assinaturas para utilização de imagens e depoimentos, no âmbito da pesquisa. Foi feita uma breve explicação sobre a peça "Macbeth" e sobre seu autor, Shakespeare, de modo a contextualizar o tempo histórico do autor e de sua produção, destacando também a atualidade e o valor de ambos. Foi lido um resumo da peça Macbeth, preparado por um dos atores do grupo de teatro. A peça foi utilizada como instrumento de sensibilização da comunidade, como uma forma de provocar os educandos, por meio da problematização, a contar suas próprias histórias, nas quais as temáticas da fábula se engendravam nos cotidianos, explicitando situações-limites, situações existenciais, contraditórias e conflituosas, carregadas de sentimentos e emoções.

Nessa peça estão consignados temas importantes, conflitantes e sempre atuais, porque ligados à essência do ser humano. São exemplos desses temas: amor, amizade, fidelidade, traição, livrearbítrio, destino e limites da violência e da ganância. A peça original funcionou como proposta de codificação porque esses são temas estampados, cotidianamente, nas páginas dos jornais, das revistas, nos programas de televisão e rádio, que conformam um ideário coletivo, embora possam ter interpretações contraditórias. Por isso, esses temas puderam ser assumidos como significativos também para essa comunidade escolar, com a perspectiva de decodificá-los e recodificá-los em novos encontros e na encenação da adaptação de Macbeth. 0 roteiro adaptado considerou os temas geradores encobertos pelas situações-limites dessa comunidade, seus interesses, suas experiências, sua realidade, orientando a organização da prática teatral-educativa e permitindo novas descodificações mais profundas e cada vez mais críticas.

\section{Análise dos debates com os educandos para criação de um espetáculo teatral}

O grupo Arte Tangível realizou uma análise dos relatos registrados nos debates, refletindo criticamente sobre eles e identificando as situações-limites e os temas geradores que poderiam ser codificados no espetáculo Macbeth de Oió (Holesgrove, 2011) e trabalhados nos encontros seguintes com os educandos.

0 título Macbeth de Oió faz uma alusão imediata à peça Macbeth, tragédia escrita por William Shakespeare. Porém, a adjetivação dada à personagem Macbeth, referenciando seu local 
de origem, possibilita pensar que se trata de uma reescritura ou de uma adaptação do texto original. 0 título anuncia, também, que a adaptação se serviu da mitologia afro-brasileira, mais especificamente a dos mitos dos deuses africanos (Orixás) e do candomblé brasileiro, para recontar a fábula de Shakespeare e remodelar as personagens presentes na obra. Tomando "Oió" como a cidade de origem da personagem Macbeth, se estabelece uma relação entre Macbeth e Xangô, orixá que teria sido o mais representativo rei dessa cidade. Xangô um dia destronou o irmão Ajacá-Dadá, e o exilou como rei de uma pequena e distante cidade. Xangô foi assim coroado o quarto rei de Oió, o "Obá" da capital de todas as grandes cidades iorubás. Vê-se, assim, que os temas centrais do texto original de Shakespeare, a sede de poder e a traição entre amigos, também estão fortemente presentes nos mitos africanos de "Oió" e de Xangô, possibilitando a conexão entre esse mundo e o de Macbeth.

A partir de então, foi sendo criado o roteiro de Macbeth de Oió, integrando a história original de Macbeth e falas dos educandos que pudessem estimular, em debates pós-espetáculo, discussões sobre as causas de algumas das situações-limites da comunidade escolar e possíveis soluções para elas. Seguiram-se a criação do espetáculo e ensaios.

\section{Encontros teatrais pedagógicos}

Os encontros mensais com a comunidade foram chamados de "Encontros Teatrais Pedagógicos". Esses encontros, inspirados nos Círculos de Cultura, são assim chamados porque são, ao mesmo tempo, momentos de prática teatral e exercícios de construção crítica de conhecimento.

Os encontros teatrais pedagógicos entre o grupo de teatro e a comunidade aconteceram no CIEJA Santana-Tucuruvi, desde abril de 2010. Cada encontro teve duas horas de duração, tendo início às $20 \mathrm{~h} 30$ e se estendendo até as $22 \mathrm{~h} 30$ (as aulas, nesse CIEJA, têm início às $20 \mathrm{~h} 15$ e terminam às 22h30), com cerca de uma hora de prática teatral (jogos e demonstrações) e uma hora reservada para debates. Tais encontros aconteceram na última terça-feira do mês, durante o período letivo e contaram com o total apoio dos gestores do CIEJA. 0 coordenador pedagógico e parte da equipe administrativa do CIEJA contribuíram na divulgação e no agendamento dos encontros e a direção da escola creditou presença aos educandos. Inicialmente, os educandos vinham de diversas salas e eram informados que poderiam ausentar- 
se a qualquer momento, caso não estivessem interessados na atividade. Os encontros receberam, em média, trinta e cinco participantes e foram conduzidos pelos quatro integrantes do grupo Arte Tangível: Luciana Saul, Thomas Holesgrove, Fernanda Voltas e Alexandre Saul.

A prática teatral se deu por meio de jogos teatrais, realizados com todos os participantes. Esses jogos trabalharam categorias importantes do fazer artístico-teatral como: ritmo, conhecimento corporal, desenvolvimento dos sentidos orgânicos e emoções, ao mesmo tempo em que sugeriam metáforas sobre a realidade cotidiana. Esse momento de prática teatral incluiu, por vezes, a demonstração de um exercício cênico que faz parte do treinamento teatral do grupo Arte Tangível, conduzido por Luciana Saul (2006). Nos debates realizados com os participantes, logo após a experiência com os jogos teatrais, os educandos foram ouvidos e a discussão versou sobre temas candentes que emergiram da prática. 0 planejamento e a realização dos encontros teatrais pedagógicos envolveram as seguintes ações:

- Levantamento, com os educandos, de temas para a discussão.

- Criação e prática de jogos teatrais que continham os temas levantados em discussões preliminares.

- Preparação de material de apoio: textos, imagens e informações adicionais que pudessem contribuir para 0 debate.

- Ensaio e discussão, do grupo de teatro, dos jogos propostos para o encontro.

- Contato com a escola, apresentação da proposta e divulgação do encontro do mês.

- Realização do encontro, com registro fotográfico e videográfico.

- Definição de encaminhamentos, com os educandos, para a realização do próximo encontro.

- Análise dos registros das discussões, preparação dos novos encontros.

- Devolutiva, para a comunidade, de imagens e produções criadas nos encontros anteriores. 
A partir de 2011, em conjunto com o coordenador pedagógico e com a anuência da professora e de uma das turmas do CIEJA, o encontro passou a ser realizado sempre com essa turma, com o objetivo de aprofundar os debates e a experiência com os jogos teatrais. Nos encontros teatrais pedagógicos, os educandos foram sempre esclarecidos sobre os objetivos da pesquisa e sobre o planejamento das atividades propostas para o dia do encontro, com o que podiam concordar ou não e ajudar a reelaborar a proposta, se fosse o caso.

Em uma proposta como essa, norteada por relações democráticas, foi importante estar atento aos princípios de participação e ao direito à informação. Assim, os estudantes foram informados sobre o andamento da produção da peça, dificuldades encontradas pelos atores e puderam, também, partilhar expectativas, desejos e frustrações em relação ao trabalho que se desenvolvia. Dessa forma, foi possível que os educandos contribuíssem constantemente com o processo criativo, por meio de discussões e análises estéticas, produção de material e novas discussões sobre as situações-limites e temas geradores, aprofundando conhecimentos e níveis de criticidade de todos os envolvidos.

\section{Apresentação de espetáculos teatrais na escola}

A escola, como entendida nesta pesquisa, é parte fundamental de um projeto democrático de cidade. Nas áreas periféricas, em especial, esta pode se tornar um centro agregador da comunidade local, muitas vezes o único equipamento público disponível em quilômetros capaz de abrigar a comunidade. Nesse contexto, um desafio que se coloca é o desenvolvimento de ações e práticas que possam ser realizadas em parceria com a escola, e que se traduzam na criação de oportunidades de democratização do acesso ao conhecimento e de sua construção para os moradores da região. Paulo Freire considera que "a escola deve ser também um centro irradiador da cultura popular à disposição da comunidade, não para consumi-la, mas para recriá-la" (Freire, 2001, p. 16).

A escola, na perspectiva freireana, é um lugar no qual se desenvolve uma prática política, ou seja, um lugar de luta e de esperança, um lugar não só para aprender conceitos, mas para encontrar, conversar, experimentar o confronto e dialogar, construindo diferentes conhecimentos. Com essa compreensão, a escola pode se constituir em um lugar especial para a apresentação 
de espetáculos teatrais, seguidos de debates, como um exercício de conhecimento e prazer estético. 0 grupo Arte Tangível considera importante a apresentação, na escola, de espetáculos concluídos e também daqueles que estão em fase de construção porque, nesse último caso, há uma intenção explícita de contemplar a participação da comunidade escolar no desenvolvimento da peça.

Desde o início desta pesquisa foram apresentados pelo Arte Tangível, no CIEJA Santana/Tucuruvi, a peça Sobre Sonhos e Esperança e, também, os três primeiros atos - ainda em fase de construção - do espetáculo Macbeth de Oió. 0 objetivo de apresentar parte da peça Macbeth de Oió, ainda inconclusa, foi abrir o processo criativo da companhia para a comunidade, com a intenção de debater, não só os temas da peça, mas também as propostas estéticas e as condições de produção teatral na cidade de São Paulo.

A encenação dos espetáculos teatrais, nessa escola, envolveu as seguintes ações de logística:

- Definição, em conjunto com os gestores da escola, do melhor dia e horário para a apresentação do espetáculo. A apresentação foi marcada em dia e horário de aula.

- Preparação de argumentos para o debate com o público.

- Verificação, com a equipe administrativa da escola, da disponibilidade do espaço para a apresentação da peça, de equipamentos técnicos (microfones e uma caixa de som, para o debate) e condições de acomodação do público.

- Preparação do local de apresentação do espetáculo com antecedência de duas horas para resolver imprevistos, montar o cenário e permitir que os educandos e educadores se sentissem à vontade com a presença dos atores.

\section{Debates pós-espetáculo}

0 debate com espectadores, no contexto da proposta do grupo Arte Tangível e desta pesquisa, tem uma importância fundamental. Nos debates é possível alongar o diálogo com o público, diálogo esse que começa com a escolha da temática e do espetáculo a ser encenado, passa pelos momentos em que a peça vai sendo construída, pela apresentação e culmina com o direito de cada um dizer a sua palavra. É um exercício excelente de escuta, 
tolerância, alegria, amorosidade, crítica, respeito e construção de conhecimento.

Os debates pós-espetáculo foram momentos de decodificação dos temas apresentados na peça e também serviram ao propósito de identificar novas situações-limites e temas geradores dessa comunidade, no momento histórico que atravessa.

\section{Considerações finais}

Todas as atividades realizadas evidenciaram aprendizado e foram momentos de troca de experiências entre todos os participantes. Os dados coletados, por meio de depoimentos, debates/diálogos, observações e entrevistas falam a favor dos objetivos estabelecidos nesta pesquisa. Os educandos adotaram uma postura curiosa diante do fazer artístico-teatral, disposição para participar e interesse em debater criticamente os temas geradores. Além disso, alguns estudantes conseguiram identificar a produção de conhecimento como uma construção histórica, social, econômica e política, no espaço/tempo desta pesquisa.

\section{REFERÊNCIAS}

APPLE, Michael W. Conhecimento Oficial: a educação democrática numa era conservadora. Tradução de Maria Isabel E. Bujes. Petrópolis: Editora Vozes, 1997.

ARELARO, Lisete; KRUPPA, Sonia. A educação de jovens e adultos. In: PORTELLA, Romualdo; ADRIÃO, Theresa (Orgs.). Organização do ensino no Brasil: níveis e modalidades na Constituição Federal e na LDB. $2^{a}$ edição rev. ampl. São Paulo: Xamã Editora, 2007.

BANDEIRA, Manuel. Nota do tradutor. In: SHAKESPEARE, William. Macbeth. Tradução de Manuel Bandeira. São Paulo: Cosac \& Naify, 2009. p. 9-11.

CHIZZOTTI, Antônio. Pesquisa qualitativa em ciências humanas e sociais. São Paulo: Editora Vozes, 2008.

FREIRE, Paulo. A educação na cidade. $5^{a}$ edição. São Paulo: Cortez Editora, 2001. 
- Criando métodos de pesquisa alternativa:

aprendendo a fazê-la melhor através da ação. In: BRANDÃo, Carlos Rodrigues (Org). Pesquisa participante. São Paulo:

Editora Brasiliense, 1981. p. 34-41.

Pedagogia da autonomia: saberes necessários à prática educativa. $37^{a}$ edição. São Paulo, 2008.

Pedagogia do oprimido. $17^{\mathrm{a}}$ edição. Rio de Janeiro:

Editora Paz e Terra, 1987.

HOLESGROVE, Thomas. Macbeth de Oió. 2011. Peça teatral. No prelo.

MCLAREN, P. Paulo Freire e pós-modernismo. Educação e Realidade. Porto Alegre, n. 21, v. 12, p. 3-13, jan.-jun. 1987.

SAUL, Alexandre. Prática teatral dialógica de inspiração freireana: uma experiência na escola, com Jovens e Adultos. 2011. Dissertação (Mestrado em Educação: Currículo) Pontifícia Universidade Católica de São Paulo (PUC-SP). São Paulo. 2011.

SAUL, Luciana. Rituais do candomblé: uma inspiração para o trabalho criativo do ator. 2006. Dissertação (Mestrado em Artes Cênicas) - Universidade de São Paulo (USP). São Paulo.

Recebido em fevereiro de 2012 Aprovado em março de 2012 